\title{
Analyzing the Impact of Video Representation Complexity on Preservice Teacher Noticing of Children's Thinking
}

\author{
Alison Superfine ${ }^{1^{*}}$, John Bragelman ${ }^{1}$ \\ ${ }^{1}$ University of Illinois at Chicago, Chicago, Illinois, USA
}

Received 29 December 2017 • Revised 10 September 2018 - Accepted 11 September 2018

\begin{abstract}
Despite the growing research base on preservice teacher noticing of children's mathematical thinking in video, few, if any studies consider the complex nature of the video representations themselves. Drawing from cognitive load theory, we developed a rubric to code the complexity of the salient teaching and learning events captured in video, and analyzed the relationship between video complexity and preservice teacher $(n=233)$ noticing. Results indicate that two categories significantly highlight children's mathematical thinking and two categories significantly mask children's mathematical thinking for preservice teachers. We discuss the implications of these results for the design of our instructional platform and other video-based learning environments used in preservice teacher education settings.
\end{abstract}

Keywords: cognitive load, preservice teacher education, teacher noticing, video

\section{INTRODUCTION}

Over the past decade, there has been a considerable increase in the use of video to support teacher learning (Brophy, 2004). Used as a representation of teaching and learning interactions, video provides a means for teachers to critically analyze teaching practice while remaining safely distanced from their own teaching practice. Further, video as a medium affords additional time for teachers to reflect on their observations while providing a narrower, more focused view of classroom interactions that privileges children's thinking (Ball \& Cohen, 1999). Researchers have utilized the construct of teacher noticing to understand what and how teachers (both inservice and preservice) learn from video, orienting on what events teachers pay attention to in video and how they reason about those events (cf. Sherin, Jacobs, \& Philipp, 2011). This research shows much promise for the use of video to support teacher learning.

However, research on preservice teachers' (PST) noticing, in particular, presents a mixed picture of effectiveness. While some research has demonstrated positive impacts on PSTs' ability to notice children's thinking, other research shows that noticing children's thinking in video is challenging for PSTs. For example, Alsawaie and Alghazo (2010) found that, when PSTs were asked to analyze video lessons with a framework, utilizing video helped PSTs to pay attention to noteworthy events in classroom interactions, and develop their ability to pay attention to children's learning when watching and analyzing a lesson. Similarly, Santagata, Zannoni and Stigler (2007) and Pang (2011) both found that the use of video enhanced PSTs' ability to attend to children's thinking beyond mere descriptions to more nuanced observations of the effects of teachers' actions on children's thinking. While not a specific focus on mathematics, Masats and Dooly (2011) in their study of the use of video case studies in a teacher education program found that PSTs reported they were better able to understand more of the complexities and nuances in teaching practice by engaging with the video case studies.

In contrast to these studies, Blomberg, Sturmer and Seidel (2011) found that PSTs struggled to reason about mathematics classroom situations. While not a specific focus on children's mathematical thinking, Blomberg and colleagues reported that, when asked to describe, explain, and make instructional predictions based on depictions in the video, PSTs were better able to reason about classroom situations focused on social science and humanities topics as compared to classroom situations focused on mathematics topics. Similarly, Castro Superfine, Li, Bragelman, and Fisher (2015) conducted a quasi-experimental study and found that PSTs in the treatment group

(C) 2018 by the authors; licensee Modestum Ltd., UK. This article is an open access article distributed under the terms and conditions of the Creative Commons Attribution License (http://creativecommons.org/licenses/by/4.0/). \amcastro@uic.edu (*Correspondence) $\$ jbragelman@gmail.com 


\section{Contribution of this paper to the literature}

- Research questions: Explore the relationship between preservice teacher noticing and video representation complexity.

- Employed methods: Use of generalized estimating equations for the analysis as it allows for repeated measures analysis, an autoregressive correlation matrix that adjusts for within-observation correlations, and an ordinal outcome variable with missing data

- Findings: Results demonstrate that preservice teachers more effectively notice children's thinking in video representations that have certain key attributes: cognitively demanding tasks that evoke multiple and different solution strategies from children; child thinking that is presented in group/simultaneous contexts rather than individually and sequentially; videos with minimal teacher interaction related to children's mathematical thinking; and videos that minimize the number of moments not related to children's mathematical thinking. These results align with cognitive load theory research - video representations that highlight children's mathematical thinking increase preservice teachers' ability to notice children's mathematical thinking while video representations that mask children's mathematical thinking overload preservice teachers' ability to notice children's mathematical thinking.

did not improve in their noticing children's mathematical thinking in video over the course of a semester. Still, Jacobs et al. (2010) found that, after taking coursework designed around opportunities for studying children's mathematical thinking in the form of video clips, at the end of the course PSTs did not provide robust evidence of attending to or interpreting children's thinking, or of deciding next instructional steps based on children's understanding. Thus, reasoning about and attending to aspects of classroom situations involving mathematics and children's mathematical thinking depicted in video seems to be challenging for PSTs.

While one commonality across these studies is the use of video, the nature of the teaching and learning interactions portrayed in some of these videos was quite different. For example, Jacobs et al. (2010) used videos of interviews with individual students in a highly controlled setting whereas Castro Superfine et al. (2015) used videos of actual classroom footage. Research on multimedia learning suggests that such differences in the nature of the video representations, including the presence of verbal and written representations of children's thinking, may contribute to the wide variation in teacher learning outcomes in the aforementioned studies (Mayer, 2003). Indeed, learning from representations of teaching is dependent on the nature of the representations and the settings in which the representations are analyzed (Hatch \& Grossman, 2009). Building on our prior work on PST noticing (Castro Superfine et al., 2015; Castro Superfine, Fisher, Bragelman, \& Amador, 2017), we explore this hypothesis using research on multimedia learning, which suggests that the cognitive processing associated with the presence or absence of multiple representations and both visual and auditory elements in video contributes to differences in learning outcomes (Mayer et al., 2003). Our aim in this work is to provide a lens through which we can characterize the nature of videos representations used in preservice teacher learning environments. Through an exploratory analysis of data collected from two semesters of a university-based mathematics course for PSTs, we explore the following research question: How do differences in video representation complexity impact PSTs' noticing of children's thinking?

\section{BACKGROUND}

\section{Defining Teacher Noticing}

While noticing generally involves attending to and making sense of particular features of an instructional setting (Sherin, Jacobs, \& Philipp, 2011), we define noticing as attending to and interpreting particular features of classroom practice. Indeed, PSTs need to learn to productively attend to pertinent features (e.g., children working collaboratively) of an instructional setting (Star et al., 2011). We are also concerned with a noticing of specific features of classroom practice, and thus focus on PSTs' noticing of CMT, as the noticing of such features of classroom practice are part of what they will do in their future work as mathematics teachers. Thus, we define PST noticing as attending to and interpreting CMT, where CMT includes any mathematical problem solving activities in which children are engaged, such as engaging in discussion about solving a problem and asking questions about and during the problem solving activity.

\section{Complexity of Video Representations}

There are many different types of video that are used in teacher learning contexts, including videos of teachers' own classrooms, videos of other teachers' classrooms, and commercially produced videos. Such video types vary in terms of how authentic the teaching and learning interactions are that are portrayed. As we have previously 
argued (Castro Superfine et al., 2017), when used in teacher learning contexts, these different types of videos are often edited for different purposes and foci, thus highlighting certain aspects of teaching and learning in the captured events while masking others. Indeed, video is a type of representation of complex teaching and learning practices, which highlights the salient teaching and learning events and at the same time fails to capture other events related to the represented events (Hatch \& Grossman, 2009). We define this simultaneous highlighting and masking as the complexity of video (Castro Superfine et al., 2017). As such, incorporating video clips that are more or less complex in terms of the nature of the teaching and learning events is particularly important for PSTs, who often struggle to pay attention to children's thinking in video (Jacobs et al., 2010), and tend to focus on aspects of pedagogy or classroom management rather than children's thinking (Star \& Strickland, 2008).

Research on mathematics teaching and learning suggests several features of classroom learning environments that may contribute to video representation complexity. For example, researchers have shown that high cognitive demand mathematical tasks present a number of instructional challenges for teachers to enact the task with children in ways that do not diminish cognitive demand (Stein et al., 2015; Tekkumru Kisa \& Stein, 2015). Characteristics of such high-demand tasks include the opportunity for children to use multiple solution strategies and representations, including non-routine strategies (Stein et al., 2000). Similarly, researchers have demonstrated that making sense of children's thinking from representations of practice is challenging for practicing teachers (Chamberlin, 2005). Moreover, research on teacher questioning and classroom discourse indicates that the questions teachers ask children during problem-solving can impact the mathematical thinking in which children are engaged. In particular, teacher questions that press children to explain why or how can making their thinking more visible during class discussions (Kazemi \& Stipek, 2001; Stein et al., 2015). Thus, the presence of features such as children engaged in solving high-demand tasks or children discussing their thinking with peers and teachers on such tasks can be difficult for observers to make sense of in video representations, particularly novice observers such as PSTs. As we posit that differences in video representation complexity have considerable implications for PST noticing in video, we utilize cognitive load theory to frame differences in complexity.

\section{Cognitive Load Theory and PST Noticing}

Research on multimedia learning suggests that the cognitive processing associated with the presence (i.e., highlighting) or absence (i.e., masking) of features, and nature of events depicted in video representations contributes to differences in learning outcomes (Mayer et al., 2003). For these reasons, we draw from cognitive load theory because it provides a model for how humans process multimedia (e.g., video) information for learning (Sweller, 2003). Visual and verbal information is processed through working memory and are limited by its constraints, primarily its finite capacity. While cognitive schemas of varying size and complexity held in long-term memory aid processing in working memory, material that is not complex can be processed individually and serially. In contrast, complex material is highly linked and interactive, and must be processed as a single element. Cognitive load theorists differentiate these as elements with high and low interactivity. For example, memorizing a sequence of numbers or shapes has low element interactivity, while processing a video displaying children's interactions with peers, a teacher, and mathematics content is highly interactive. Expertise derives from knowledge stored in schemas in long-term memory, so it follows that novice learners, such as PSTs, do not have schemas to rely upon while processing complex material with high element interactivity relating to noticing CMT. When schemas are not present, the load on the learner's working memory increases. In other words, attending to and interpreting CMT is a difficult task for PSTs because they are required to process the dynamic and complex environment of an authentic school classroom, recognize what is and what is not CMT, and interpret it all within the limits of their working memory.

Cognitive load theory distinguishes between three types of load (Paas, Renkl, \& Sweller, 2003; Sweller, 2003). Complex material with high element interactivity is the driving force behind intrinsic load; it is the material being learned. In contrast, any elements not directly pertaining to the material being learned add to the load on the learner; this type of cognitive load interferes with schema acquisition, as learners must process unnecessary, extraneous elements. Operationalized, extraneous load is the mental effort imposed by the instructional activities, their design, and presentation (Lee, Plass \& Homer, 2006). For example, it is the load imposed on a learner by an unintuitive mathematics task, the contextual, nonmathematical elements of a task, or the noise created by other children in the learning environment. In our work, the presence of children are discussing unrelated issues or engaging in off-task behavior can contribute to the extraneous load of noticing CMT. Finally, the mental effort required by the learners to process new material into long-term memory, building or integrating it into existing schema is called germane load. This type of load extends beyond processing elements solely in working memory, like intrinsic load. In other words, it is the cognitive processing required by a PST to connect a child's novel problem solving strategy to their mathematical understanding (e.g., this child understands the role of place value in the multiplication algorithm). 
The three types of cognitive loads compete for available working memory and are additive in nature (Paas et al., 2003), and thus comprise the cognitive demand of the task for learners. In other words, performing the task (i.e., noticing CMT), the additional information that comes with situating the task in an authentic classroom on video, and processing the information related to noticing CMT to long-term memory compete for a finite amount of space in working memory. Intrinsic load serves as a baseline for the difficulty of the material being processed, and it is irreducible. The extraneous and germane loads of the task compete for the remaining working memory. Instructional designers of multimedia learning tasks generally seek to minimize extraneous load and increase germane load. It is worth noting that lower extraneous load is not always 'better' for supporting learning outcomes (see de Jong (2009) for a critique of the three types of cognitive load). Nevertheless, sometimes the demand of the task exceeds the capacity of the learner, resulting in cognitive overload.

Research on multimedia learning outlines several scenarios where overload can occur that have implications for noticing features of classroom learning environments in video representations. For example, the intrinsic load of the task overloads one or both channels (Mayer \& Moreno, 2003). In our work, this scenario can happen when children are verbally expressing their thinking, in writing, or both. Overload can also occur when the combined intrinsic and extraneous load of the task overloads one or both channels; and the load of the task can overload one or both channels by requiring the learner to hold information in working memory for an extended period of time (Mayer \& Moreno, 2003). In our work, this scenario can happen when the amount of information to attend to becomes overwhelming, such as when multiple moments of CMT happen simultaneously or when multiple moments of CMT happen one right after another in a short period of time.

Taken together, this research suggests that authentic video representation of classrooms where children are using solution strategies to solve a problem and representing those strategies in different ways may result in cognitive overload for PSTs, thus negatively impacting their ability to notice CMT.

\section{Cognitive Load as a Lens for Understanding Video Representation Complexity}

Drawing on the aforementioned cognitive load research and teacher noticing research, we developed a video complexity rubric in Table 1 that accounts for the features of authentic school classroom video discussed in the previous section. Existing frameworks characterize video clips that focus on both teacher instructional moves and children's understanding (e.g., Sherin, Linsenmeier, \& van Es, 2009). The video clips used in our work were edited to focus explicitly on CMT, and not teaching moves. Existing frameworks also do not consider the presence of nonmathematical or non-pedagogical aspects of captured events often present in authentic video of classrooms (e.g., off-task behavior, loud speaker announcements), which is particularly important for PSTs as they do not recognize noteworthy events or interactions. For these reasons, we needed a framework that was applicable to a particular type of video (i.e., of other teacher's teaching), that made salient a particular focus of video (i.e., CMT), and that considered the presence of non-mathematical or non-pedagogical aspects of authentic classroom learning environments. Included in Table 1 are the categories and definitions under the dimensions of intrinsic and extraneous load.

The first dimension of the rubric is intrinsic load, which refers to the cognitive load of noticing (i.e., attending and interpreting) CMT in video. The intrinsic load dimension consists of six categories that contribute to the intrinsic load of the video.

Depth of enacted task. This category refers to the nature of the mathematics being discussed, and what makes it challenging for a viewer to understand. Specifically, depth of enacted task refers to the number of mathematical ideas or concepts that are being discussed in the video, the number of different representations that are being used as part of children's problem solving, and the presence of errors or misconceptions in children's mathematical thinking. For example, children might be discussing different solution strategies for solving a problem, or discussing a unique or non-standard algorithm. Such features of mathematical activity are consistent with high cognitive demand tasks, which pose a number of instructional challenges for teachers (Stein, Smith, Henningsen, \& Silver, 2000). Thus, we posit that the depth of the enacted task as viewed in video may pose similar challenges for PST noticing of CMT.

Clarity of children's thinking. This category refers to how easy it is to understand the mathematics children are communicating in the video. Drawing from Sherin, Linsenmeier and van Es (2009), this category refers to how transparent CMT is that is being discussed in the video. For example, is the child's explanation clear, or is it unclear what the child is thinking because their explanation is unclear or confusing. We posit that the clarity with which children are communicating their thinking may influence the extent to which PSTs are able to attend to and/or interpret CMT in the video.

Teacher participation. This category refers to the nature of the teacher's verbal contributions as related to CMT present in the video. Specifically, teacher participation refers to how the teacher asks questions to children in the video, and the extent to which teacher questions elicit children's thinking. For example, a teacher might ask 
Table 1. Video complexity rubric

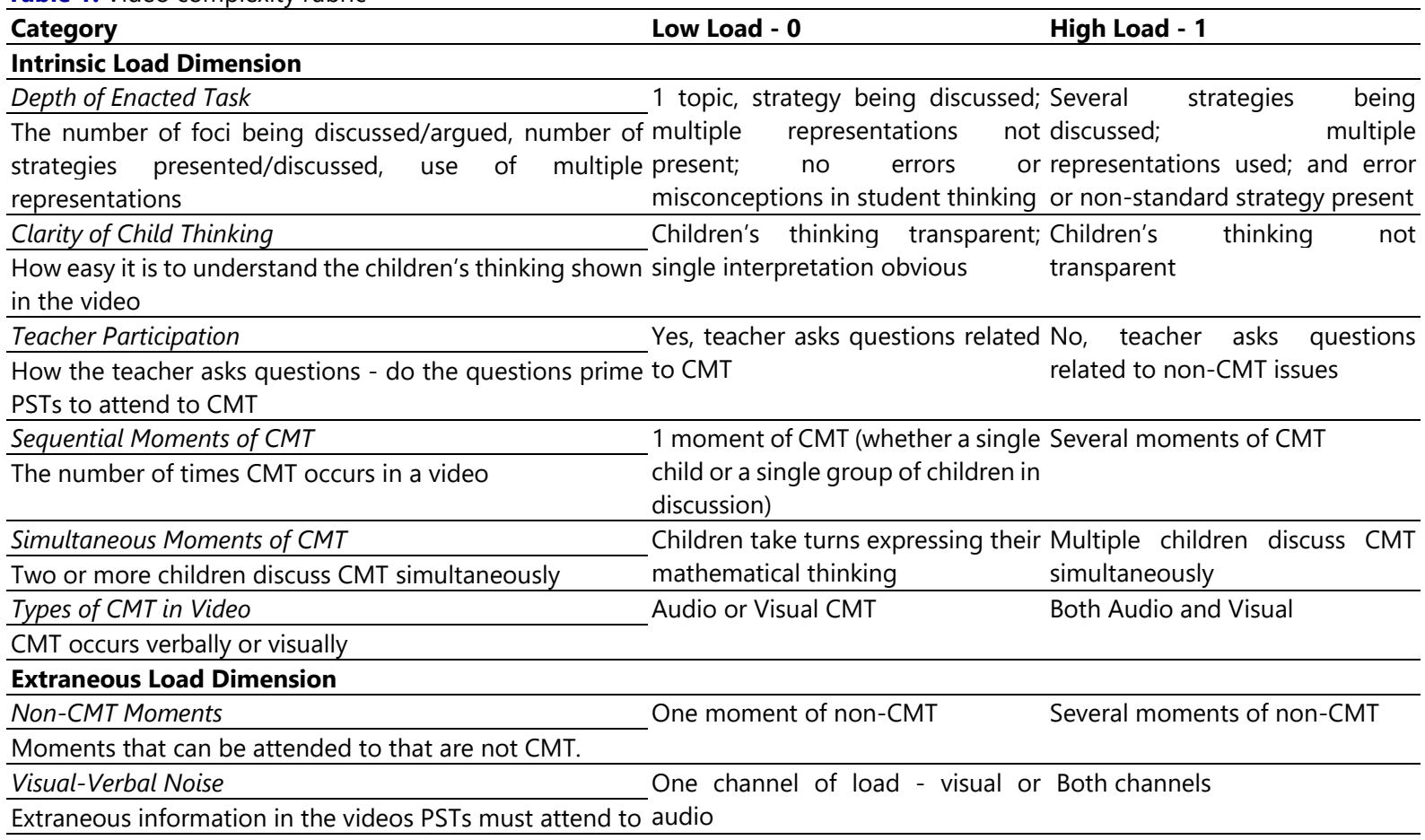

questions to a group of children that elicit their solution strategies or their thinking about a task in ways that highlight CMT. We posit that the extent of teacher participation may position PSTs to more effectively notice CMT.

Sequential moments of CMT. This category refers to the number of times instances of CMT appear in the video. Specifically, sequential moments refers to whether there is one moment of CMT present in the video, either one child or one group of children discussing a solution strategy, or whether the video features several moments of CMT. For example, a video may show one group of children discussing a task and then pan to a different group discussing a task. In this example, there are two distinct instances of CMT present in the video. Indeed, research suggests that when moments of CMT occur sequentially, without break, PSTs are required to process the CMT of the first occurrence and hold the representation of the first instance of CMT in working memory while viewing and processing the second occurrence (Mayer \& Moreno, 2003). This overloads the PST's working memory, reducing their capacity to process both instances of CMT. Thus, we posit that the more moments of CMT present in a video increases the intrinsic load of the task of noticing for PSTs.

Simultaneous moments of CMT. This category refers to the presence of multiple children discussing their mathematical thinking simultaneously. Similar to the previous category, research suggests that one channel can be overloaded by simultaneous processing, such as watching children solve a math problem in a video and reading the on-screen text describing how children solve the problem (Mayer \& Moreno, 2003). This split-attention effect (Chandler \& Sweller, 1992) degrades the cognitive capacity to process both instances. Thus, we posit that when multiple children are expressing their mathematical thinking at the same time, this increases the intrinsic load of the task of noticing CMT for PSTs.

Types of CMT. This category refers to whether CMT is expressed visually (in writing) and verbally in the video. For example, children may only verbally communicate how they are thinking about a task during a class discussion, or they may use both a written strategy and verbal communication to express how they solved a task. Research suggests that when both the visual and verbal channel require cognitive processing, this leads to an overload of the capacity of working memory, where the processing demands are not met (Mayer \& Moreno, 2003). In the context of noticing CMT, a video can overload a PST's cognitive capacity when it displays CMT visually, such as when a child's work is shown, while the child simultaneously discussing their work with a classmate or teacher degrades the PST's ability to notice the CMT.

The second dimension of the rubric is extraneous load, which refers to the cognitive processing that is not required to make sense of the CMT in the video but is relevant and necessary as context. Because our videos are of authentic school classrooms, the contextual factors include interactions not directly related to instruction, such as a teacher telling a student to speak louder, students talking during group work, or announcements made over the intercom. The extraneous load dimension consists of two categories that contribute to the extrinsic load of the video. 
Non-CMT moments. This category refers to the presence of moments that do not involve CMT. For example, children may be engaged in an off-task activity in the video, or the teacher may be dealing with classroom management issues. As research suggests, such moments can be attended to by PSTs (e.g., Star \& Strickland, 2008), but do not involve CMT. Thus, we posit that the presence of non-CMT moments increases the extraneous load of the task of noticing for PSTs.

Visual-verbal noise. This category refers to any extraneous information that is present in the video to which PSTs may attend. Specifically, visual-verbal noise includes any non-CMT related visual or audio information that is present in the video. For example, an announcement over the loud speaker, a phone call, or other interruptions are noise that PSTs may attend to but are not related to CMT. Research suggests that processing too much extraneous information may limit the ability to process relevant information for learning (Mayer \& Moreno, 2003). Thus, we posit that the presence of extraneous information in a video limits a PST's ability to notice and process children's mathematical thinking.

In short, research on multimedia learning and cognitive load theory both suggest that the cognitive processing associated with the presence (i.e., highlighting) or absence (i.e., masking) of features and nature of events depicted in video representations contributes to differences in learning outcomes. Drawing from this research, we shift the focus of research on PST noticing to better understand how video representation complexity accounts for the mixed results in extant research.

\section{METHODS}

Data for this study comes from a larger project involving the design and implementation of a video-based curriculum situated in a university-based mathematics content course for PSTs. The videos were designed and edited to highlight CMT in authentic school classroom settings. See Appendix A for a description of the videobased curriculum. The larger study examined between and within group differences when the video-based curriculum was implemented as an instructional intervention (see Castro Superfine et al., 2015). In the current study, we focus on a subset of data collected, specifically PSTs' responses to focus questions for the different videos, and the cognitive load ratings of the videos.

\section{Mathematics Content Course}

The content course is the first of two required content courses in the preservice elementary teacher program at a large university in the United States. PSTs take the course during their first or second year of study at the university, and the course precedes the mathematics methods course typically taken later in the program, in the fourth or fifth year. The course focuses on developing PSTs' mathematical knowledge for teaching that includes developing specialized content knowledge involving opportunities for PSTs to analyze children's errors, to link representations to mathematical ideas, to understand and react to mathematical thinking different from their own, and other tasks of teaching (Ball, Thames, \& Phelps, 2008). The mathematical content includes place value, whole and rational number operations, proportional reasoning, and certain aspects of number theory. A typical semester includes 29, 120 minute class periods. A range from 15 to 30 PSTs enroll in the course in any given semester, with a majority being female students. The same instructor taught both of the courses in the current study.

\section{BLINDED Scaffold Design}

As we have described in our previous work (Castro Superfine et al., 2017), the BLINDED online platform includes three scaffold levels that support a shift across noticing levels, moving from providing non-evidence-based descriptive comments to highlighting noteworthy events that attend to children's mathematical thinking. The first scaffold level supports PSTs' transition from baseline level of noticing to a mixed level of noticing (i.e., descriptive comments with some interpretation). Pop-up boxes with questions appear in the video when a moment related to CMT occurs, prompting PSTs to respond to those questions in the platform, as shown in Figures $\mathbf{1}$ and 2. This design allows opportunities for PSTs to make sense of CMT moments in the videos without expecting PSTs to highlight those events on their own. Highlighting noteworthy events is a hallmark of mixed level noticing and higher (van Es, 2011), and thus we do not expect PSTs to be able to do so in the first scaffold level. There are three videos in the first scaffold level. 


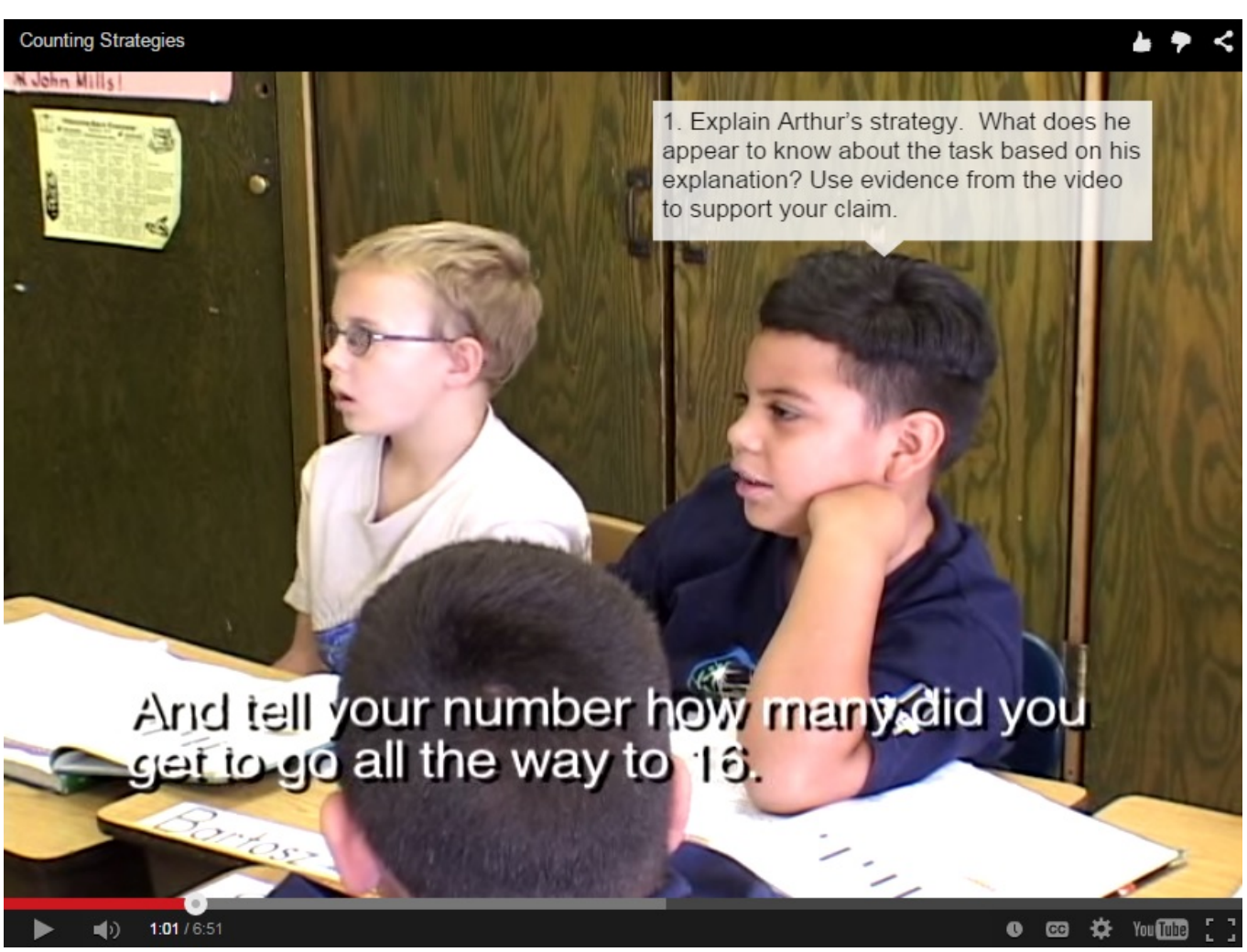

Figure 1. Example of pop-up question in the video

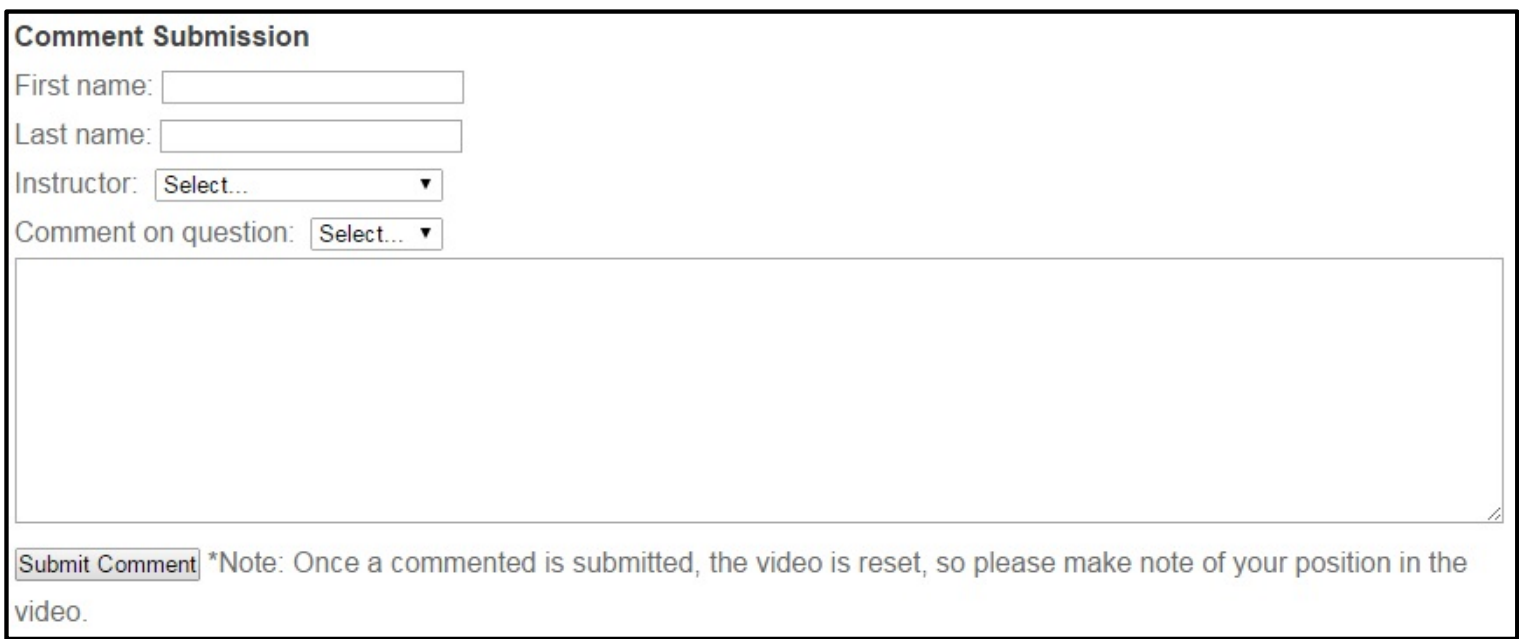

Figure 2. Platform comment section for PST responses for first scaffold level

The second scaffold level requires PSTs to take over the identification of CMT moments, as displayed in Figure 3. By the time they encounter the second scaffold, PSTs have had multiple opportunities to view important moments that are pre-selected and have responded to multiple focus questions that are targeted to CMT. There are three videos in the second scaffold level. Finally, in the third scaffold level, the in-class discussion portion is shifted to an online discussion, thus promoting interactions among PSTs in the course and removing the instructor as a facilitator of the video discussion. There are two videos in the third scaffold level. 


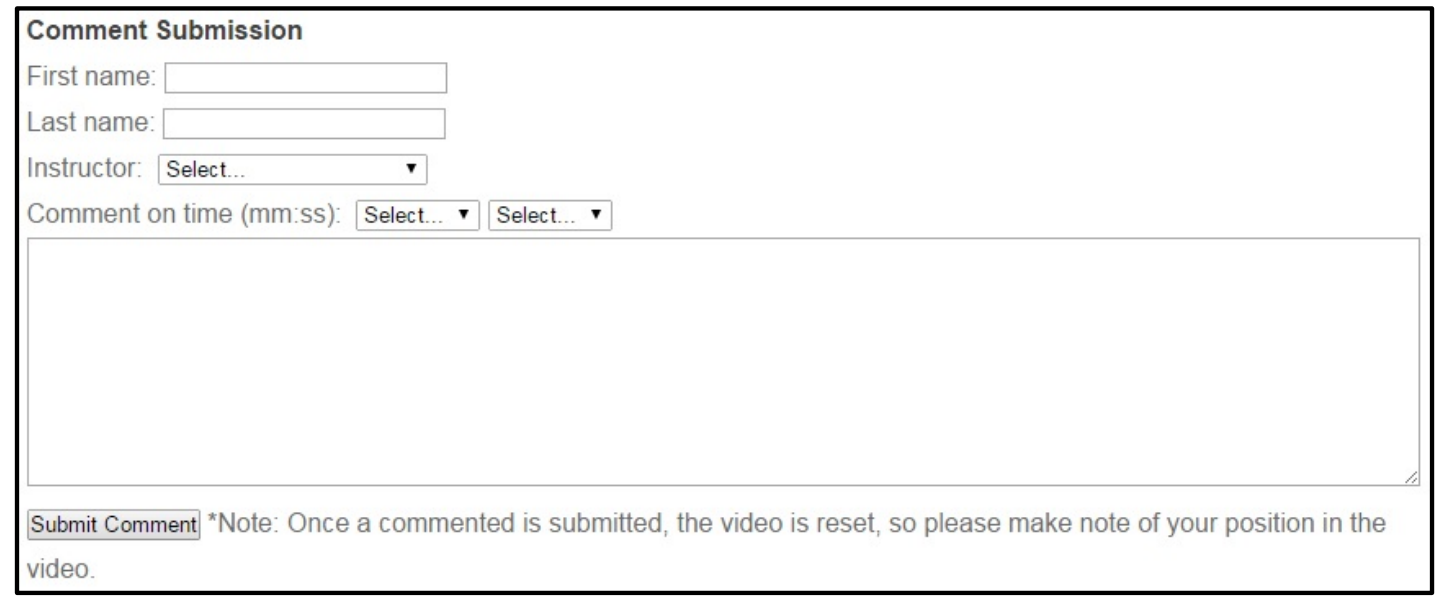

Figure 3. Platform comment section for PST responses for second scaffold level

Table 2. Examples from the first stage of coding

PST Comment $\quad$ Code

The relationship between these two methods is that you use both methods at the same time when you are Did not notice CMT working on either method. For example when You are using the "shortcut" method in your head you can picture the blocks as you borrow from one column to the other, because the way barrowing is shown on the "shortcut" method is the same as trading when using the base-10 blocks.

From what I understood Jackie wants to represent both numbers and then take away what she is being asked Noticed CMT for and then she would take it away from both the top and the bottom. It would be a valid subtraction but I personally think it would be confusing to do and you can easily make a mistake and get the wrong answer.

\section{Participants}

Participants were recruited from PSTs who enrolled in the content course during two semesters across the 20142015 school year. A member of the research team recruited them during the first week of class. There were 72 PSTs in the fall semester of the course and 161 PSTs in the spring semester of the course. Both groups experienced identical curricula in the course, including the video-based intervention.

\section{Data Analysis}

As in our previous work (Castro Superfine et al., 2015, 2017), we followed a 2-stage coding scheme to examine the extent to which PST responses or answers to the video focus questions attended to and interpreted CMT. The first stage assessed whether a PST's response described what the children were doing or saying about mathematics. Two coders were assigned to each video, and there was a greater than $90 \%$ reliability in the first round of coding. All discrepancies were reconciled through discussion until $100 \%$ agreement was achieved. Examples of comments for each code are shown in Table 2.

The second stage of coding explored the degree of evidence for attending to and interpreting CMT in the PST's response. Recall that the definition of noticing used in our work is attending to and interpreting CMT. Drawing from Jacobs et al. (2010), we developed three categories to describe the depth of attending to CMT: no evidence, limited evidence, and robust evidence. A response with no evidence of attending did not describe details about how the children solved the task or the solution strategies used. A response with limited evidence of attending included details of how the children solved the task or the solution strategy used. A response with robust evidence of attending included the children's method of problem solving, the solution strategy, and some inference or interpretation that provides a rationale for the nature of children's understanding or other factors that may have contributed to the children's understanding exhibited in the video. The same two coders were used in this stage, and there was an $80 \%$ reliability in the first round of coding. Once, again, 100\% reconciliation was achieved after discussion. Examples of comments for each code are shown in Table 3. 
Table 3. Examples from the second stage of coding

PST Comment

From what I understood, Jackie's problem is valid. She's using to technique of eliminating pieces that she sees from each group. My only concern is when she gets to the tens and ones column she will need to borrow, No Evidence which does not support her idea.

I believe that students learned the idea that they can used multiple ways to show subtraction, and that they will come up with the same answer. In the video it showed the short cut method and the base 10 system, and Limited Evidence when they were both used students came up with the same answer.

I think DeMarco understands that one skinny is equal to 10 bit since he understood that the two could be interchangeable. He knew that in order to subtract 5 bits from 124 there needed to be enough bits present to Robust Evidence subtract from. That is why he switched one skinny in for 10 bits.

Table 4. Degree of PST noticing

\begin{tabular}{ccc}
\hline Noticing & Degree of Evidence & Level of Noticing \\
\hline Did not notice CMT & & 0 \\
\hline Noticed CMT with - & No Evidence & 1 \\
\hline & Limited Evidence & 2 \\
\hline & Robust Evidence & 3 \\
\hline
\end{tabular}

Table 5. Coding results for cognitive load by video and scaffold

\begin{tabular}{|c|c|c|c|c|c|c|c|}
\hline & \multicolumn{3}{|c|}{ Scaffold 1} & \multicolumn{2}{|c|}{ Scaffold 2} & \multicolumn{2}{|c|}{ Scaffold 3} \\
\hline & Counting & Subtraction & Errors & Fractions & Remainders & Patterns & Representations \\
\hline \multicolumn{8}{|l|}{ Intrinsic Load } \\
\hline Depth of Enacted Task & 1 & 1 & 1 & 1 & 0 & 1 & 1 \\
\hline Clarity of Student Thinking & 0 & 0 & 1 & 1 & 0 & 0 & 1 \\
\hline Teacher Participation & 0 & 0 & 0 & 1 & 0 & 0 & 0 \\
\hline Moments of CMT & 1 & 1 & 1 & 1 & 1 & 1 & 1 \\
\hline Simultaneous Moments of CMT & 0 & 0 & 1 & 0 & 0 & 0 & 1 \\
\hline Types of CMT in Videocase & 0 & 1 & 1 & 1 & 1 & 1 & 1 \\
\hline \multicolumn{8}{|l|}{ Extraneous Load } \\
\hline Non-CMT Moments & 1 & 1 & 1 & 1 & 0 & 0 & 0 \\
\hline Visual-Verbal Noise & 0 & 1 & 0 & 0 & 0 & 1 & 1 \\
\hline
\end{tabular}

This coding scheme suggests an ordinal progression of PST noticing as shown in Table 4.

Using the video complexity rubric described previously, two coders scored each video as low or high on the load-noticing categories and reconciled discrepancies. Seven total videos were coded, ultimately reaching $100 \%$ agreement. Videos were grouped by scaffold level as each scaffold supported PSTs' noticing at different levels and would impact intrinsic load of the videos (van Merriënboer et al., 2003). Table 5 shows the resulting cognitive load ratings.

The data presented unique constraints for the analysis. PSTs had the opportunity to make zero or more responses for each video as part of their assignment, and they had the opportunity to choose what questions and moments to which to respond, depending on the scaffold level. PST responses for each video assignment represented repeated observations of their noticing. It stands to reason that PST responses within a video are highly correlated and not independent. PST responses within a scaffold level should have higher correlation than responses across scaffold levels, and PST responses made at smaller time intervals (such as the case of videos administered two weeks apart versus 10 weeks) will have higher correlation of noticing characteristics. Lastly, as discussed above, PSTs' noticing as a dependent variable is ordinal. Considering these constraints, we utilized generalized estimating equations (GEE) for the analysis as it allows for repeated measures analysis (Zeger \& Liang, 1986), a working, autoregressive correlation matrix that adjusts for within-observation correlations (Fitzmaurice, Laird, \& Rotnitzky, 1993), and an ordinal outcome variable with missing data (Kenward, Lesaffre, \& Molenberghs, 1994). It is worth noting that GEE provides marginal (population) estimates of the regression coefficients. Utilizing SPSS, level of PST noticing served as the response variable for all analyses. Scaffold level, video, and unique PST response served as the within subject variables in the GEE models. Overall, 233 PSTs made 1115 comments across the three scaffold levels and seven videos.

\section{RESULTS}

Two GEE models were produced. The first model resulted in two redundant covariates: Sequential Moments and Visual-Verbal Noise. As including redundant covariates reduces accuracy in estimation and inference for the 
Table 6. Parameter estimates, standard errors (SE), Wald statistics ( $\chi^{2}$, degrees of freedom), corresponding significance probabilities (p), and log odds ratio from the analyses

\begin{tabular}{lccccc|ccccc} 
& \multicolumn{5}{c}{ Model 1 } & \multicolumn{5}{c}{ Model 2 } \\
\cline { 2 - 12 } Parameter & Est. & SE & $\begin{array}{c}\text { Chi Square } \\
\text { (df) }\end{array}$ & $\mathbf{p}$ & Exp(B) & Est. & SE & $\begin{array}{c}\text { Chi Square } \\
\text { (df) }\end{array}$ & p & Exp(B) \\
\hline Depth of Enacted Task & 0.268 & 0.171 & $2.463(1)$ & 0.117 & 1.307 & 0.322 & 0.122 & $6.977(1)$ & 0.008 & 1.308 \\
\hline Clarity of Student Thinking & 0.060 & 0.153 & $0.155(1)$ & 0.694 & 1.062 & & & & \\
\hline Teacher Participation & 0.600 & 0.168 & $12.715(1)$ & 0.000 & 1.821 & 0.614 & 0.106 & $33.254(1)$ & 0.000 & 1.847 \\
\hline Sequential Moments of CMT & - & - & - & - & - & & & & & \\
\hline Simultaneous Moments of CMT & 0.147 & 0.104 & $1.997(1)$ & 0.158 & 1.158 & 0.156 & 0.073 & $4.496(1)$ & 0.034 & 1.168 \\
\hline Types of CMT in Videocase & -0.078 & 0.101 & $0.608(1)$ & 0.435 & 0.925 & & & & & \\
\hline Non-CMT Moments & -0.518 & 0.121 & $18.317(1)$ & 0.000 & 0.596 & -0.527 & 0.080 & $43.339(1)$ & 0.000 & 0.591 \\
\hline Visual-Verbal Noise & - & - & - & - & - & & & & & \\
\hline
\end{tabular}

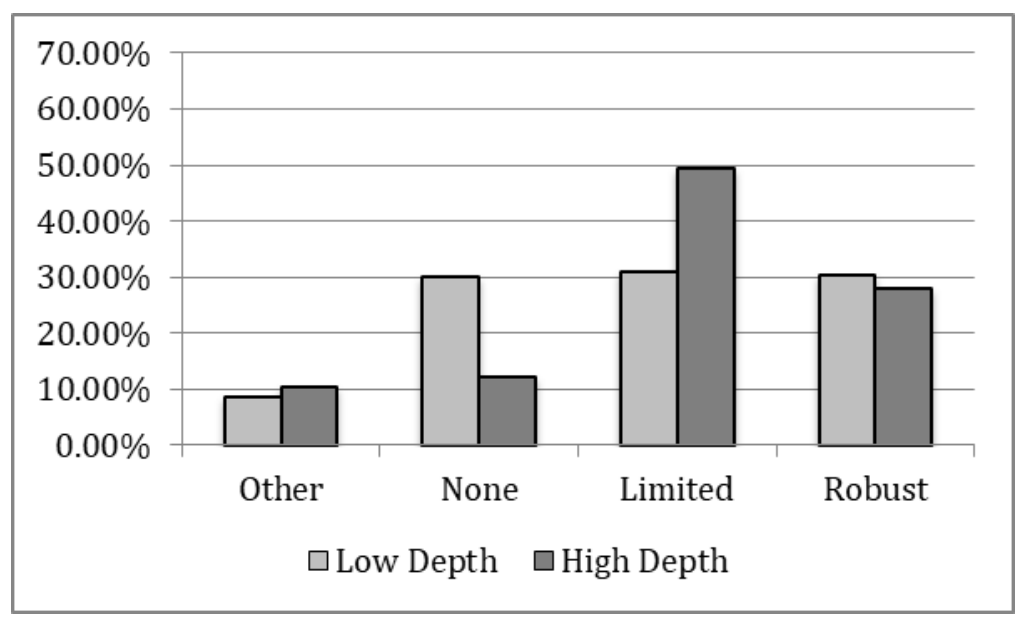

Figure 4. Distribution of PST responses by low and high Depth of Enacted Task

model (Inan \& Wang, 2017), they were removed for the second model. Following a backward progression for covariate elimination, Clarity of Children's Thinking and Types of Moments were also removed for the second model with results in Table 6. Four cognitive load criteria from our initial rubric significantly predict the population of PSTs' level of noticing: Depth of Enacted Task, Teacher Participation, Simultaneous Moments of CMT, and NonMoments of CMT.

Overall, these results suggest that certain categories of intrinsic and extraneous cognitive load of the video significantly impacted what PSTs noticed and the level at which they noticed CMT. Specifically, the categories of Depth of Enacted Task, Teacher Participation, Simultaneous Moments of CMT, and Non-CMT Moments significantly affected how PSTs noticed CMT. We elaborate on these results below.

\section{Depth of Enacted Task}

The intrinsic cognitive load category, Depth of Enacted Task, significantly impacts PSTs' level of noticing $\left(\beta_{1}=\right.$ $\left..322, \chi^{2}=6.977, d f=1, p=.008\right)$. The log odds ratio suggests the population of PSTs are 1.380 times more likely to attend to CMT at a higher level in a video with multiple enacted strategies or mathematical representations present than a video including only one enacted strategy or representation. The relative distribution of 1115 PST responses across the levels of noticing by Depth of Enacted Task is shown in Figure 4. This outcome suggests a video with a high Depth of Enacted Task resulted in a higher percentage of PST responses that attended to CMT and described the strategy being implemented by the child(ren). In other words, a PST can attend to CMT with a description of the strategies if more opportunities to do so are presented to the PST in the video.

\section{Teacher Participation}

The intrinsic cognitive load category Teacher Participation significantly impacts PSTs' level of noticing $\left(\beta_{2}=\right.$ $\left..614, \chi^{2}=33.254, \mathrm{df}=1, \mathrm{p}=.000\right)$. The log odds ratio suggests the population of PSTs are 1.846 times more likely to attend to CMT at a higher level in a video where the teacher does not ask questions to elicit CMT than a video where a teacher does. The distribution of 1115 PST responses across the levels of noticing by Teacher Participation is presented in Figure 5. This outcome suggests the presence of a teacher in a video who asks questions to elicit 


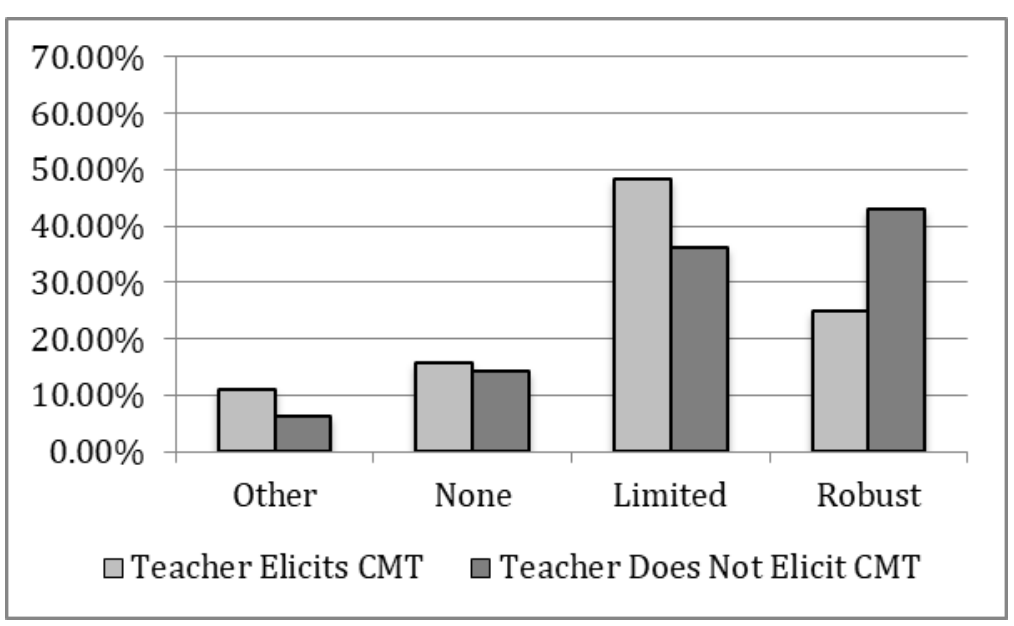

Figure 5. Relative distribution of PST responses when a teacher asks questions to elicit CMT

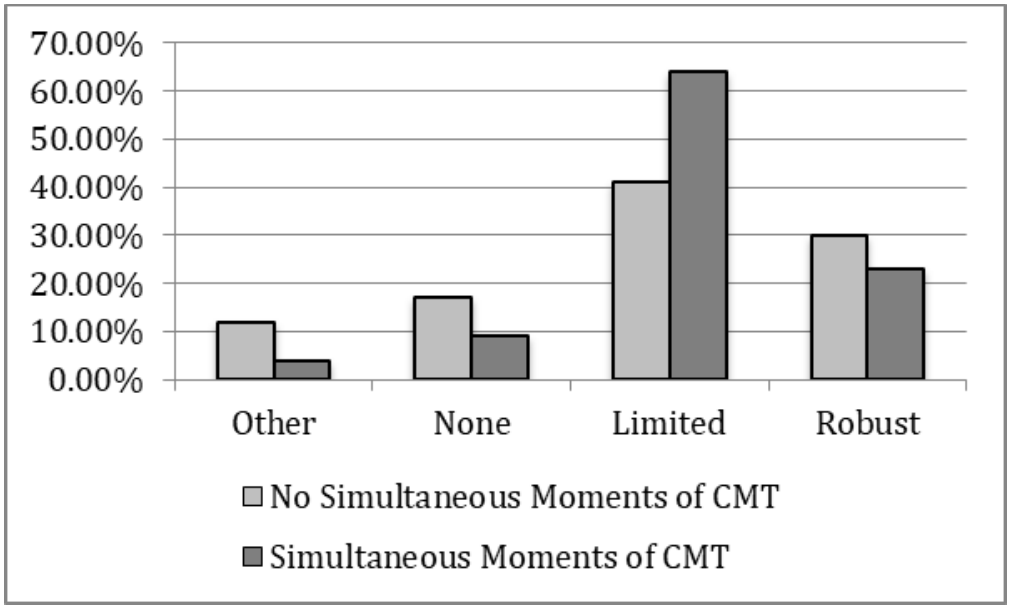

Figure 6. Relative distribution of PST responses when video has Simultaneous Moments of CMT

CMT lowers the level of noticing by the population of PSTs. In other words, PSTs seem to attend to CMT at a higher level when a teacher is not asking children questions to elicit their thinking.

\section{Simultaneous Moments of CMT}

The intrinsic cognitive load category Simultaneous Moments of CMT significantly impacts PSTs' level of noticing $\left(\beta_{5}=.156, \chi^{2}=4.496, d f=1, p=.034\right)$. The log odds ratio suggests the population of PSTs are 1.168 times more likely to notice CMT at a higher level in a video where simultaneous moments of CMT occur than a video where only one moment of CMT occurs at any point in time. The distribution of 1115 PST responses across the levels of noticing by Simultaneous Moments of CMT is presented in Figure 6. Aligning with the findings of the Depth of Enacted Task category, this outcome suggests the population of PSTs notice CMT at a higher level if more opportunities for noticing CMT are present, even when simultaneously presented in a video.

\section{Non-Moments of CMT}

The intrinsic cognitive load category, Non-Moments of CMT, significantly impacts PSTs' level of noticing $\left(\beta_{7}=\right.$ $\left.-.527, \chi^{2}=43.339, d f=1, p=.000\right)$. The log odds ratio suggests the population of PSTs are 591 times less likely to notice CMT at a higher level in a video where several non-moments of CMT occur than a video where only one non-moment of CMT occurs. The distribution of 1115 PST responses across the levels of noticing by Non-Moments of CMT is presented in Figure 7. This finding suggests non-moments of CMT in videos present additional, extraneous cognitive load on the population of PSTs and reduces the level of noticing CMT by the population of PSTs. 


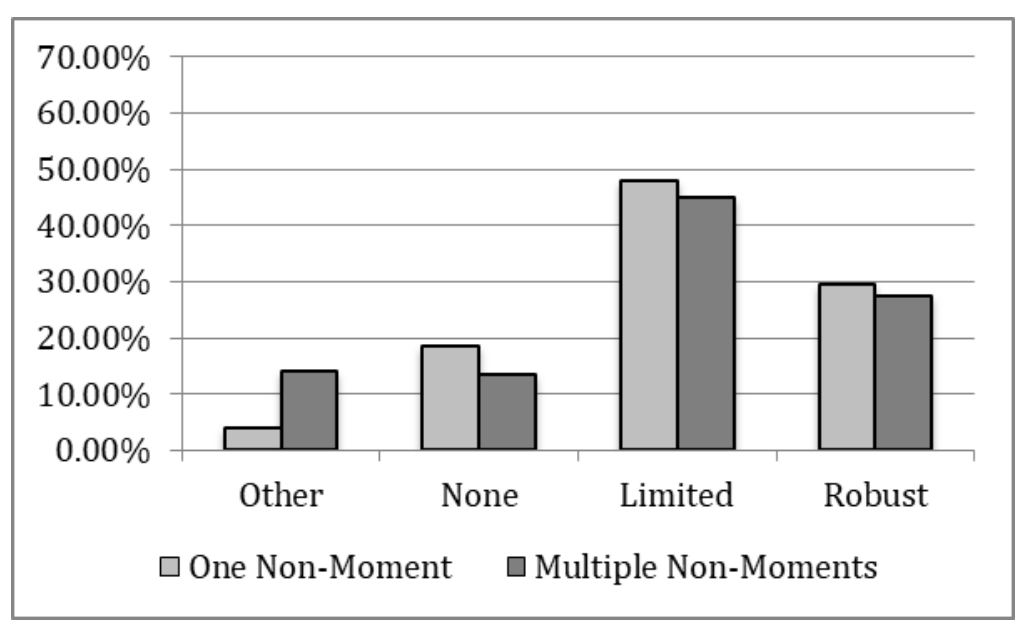

Figure 7. Relative distribution of PST responses when video has multiple moments without CMT

\section{DISCUSSION AND CONCLUSION}

As learning from representations of teaching are dependent on the nature of the representations and the settings in which the representations are analyzed (Hatch \& Grossman, 2009), our aim in this study is to understand how video representation complexity impacts PST noticing of CMT. Drawing from cognitive load theory, we developed a rubric for analyzing the complexity (i.e., simultaneous highlighting and masking) of the salient teaching and learning events captured in video. Through an exploratory analysis, we focused on the following question: How do differences in video representation complexity impact PSTs' noticing of children's thinking? Results of our analysis suggest that certain dimensions of complexity impact PST noticing, particularly the presence (i.e., highlighting) or absence (i.e., masking) of certain features in the video representations. Further, our results suggest that these dimensions do not necessarily align with the binary categories of intrinsic and extraneous load. In other words, high intrinsic load does not always equate to highlighting nor does high extraneous load equate to masking. We elaborate on these results below.

In authentic video representations of classrooms, our results indicate there are certain intrinsic load categories that seem to highlight CMT and positively impact PST noticing. For example, the Depth of Enacted Task category positively impacted PST noticing; that is a PST can attend to CMT and provide a description of the CMT if multiple solution strategies are present in the video, including novel solution strategies and incorrect solution strategies. Simultaneous Moments of CMT also significantly impacted PST noticing in that PSTs notice CMT at a higher level when multiple children are discussing their solution strategies simultaneously, such as in small groups. Together, these results suggest that in the case of developing PSTs' skills at noticing CMT, videos that highlight CMT do so by providing abundant opportunities, even to the point of potentially overloading PSTs with simultaneous opportunities (Mayer \& Moreno, 2003).

In contrast, the category of Teacher Participation within intrinsic load did not highlight CMT. Specifically, we found that Teacher Participation negatively impacted PST noticing in that PSTs seem to attend to CMT at a higher level when a teacher is not asking children questions to elicit their mathematical thinking or when a teacher is not present, and PSTs seem to attend to CMT at a lower level when a teacher is asking children questions to elicit their mathematical thinking. Our initial hypothesis was that the presence of such teacher interactions in video would improve PST noticing in that teacher questions would scaffold PST noticing. However, results of our study suggest the presence of a teacher asking questions that prime CMT in the video overloads PSTs' ability to notice children's thinking. In this sense, we posit that a teacher's participation potentially masks CMT for PSTs, making it difficult for them to notice CMT at a high-level.

Finally, in terms of categories under extraneous load, only Non-Moments of CMT negatively impacted PST noticing. Indeed, when non-moments of CMT were present in our video representations, PSTs attended to those moments. Taken together, with the results under the intrinsic load dimension, videos that highlight CMT provide PSTs ample, salient opportunities to notice CMT, even simultaneously and to a high degree of depth, while videos that mask CMT do so by providing PSTs opportunities to attend to moments that are not related to CMT, even when the video attempts to make CMT more salient, such as when a teacher asks questions to elicit CMT. 
Table 7. Realigned video complexity rubric

$\begin{array}{lll}\text { Scaffold } 1 & \text { Scaffold 2 } & \text { Scaffold 3 }\end{array}$

Counting Subtraction Errors Fractions Remainders Patterns Representations

\begin{tabular}{lccccccc}
\hline & Counting & Subtraction & Errors & Fractions & Remainders Patterns Representations \\
\hline Highlight CMT & & & & & & \\
\hline Depth of Enacted Task & 1 & 1 & 1 & 1 & 0 & 1 & 1 \\
\hline Simultaneous Moments of CMT & 0 & 0 & 1 & 0 & 0 & 0 & 1 \\
\hline Mask CMT & & & & & & & \\
\hline Teacher Participation (Reverse Effect) & 1 & 1 & 1 & 0 & 1 & 1 & 1 \\
\hline$\quad$ Non-CMT Moments & 1 & 1 & 1 & 1 & 0 & 0 & 0 \\
\hline
\end{tabular}

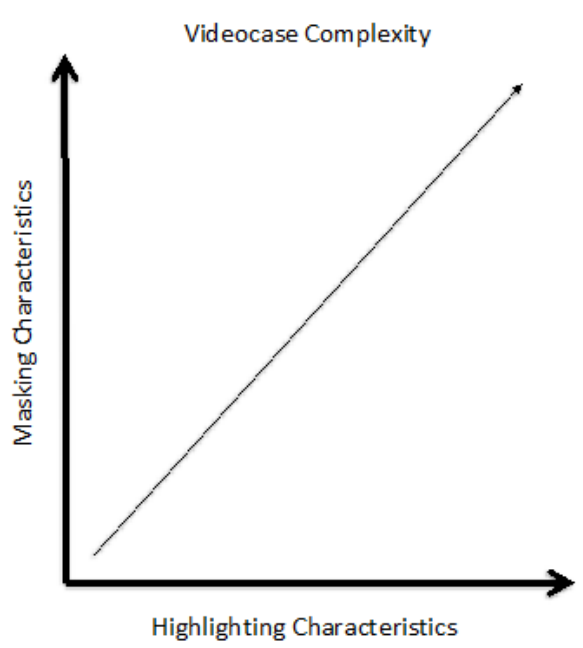

Figure 8. Videocase complexity as a function of masking and highlighting characteristics

Table 8. Overall scores for highlighting and masking dimensions

\begin{tabular}{lccccccc}
\hline & & Scaffold 1 & & \multicolumn{2}{c}{ Scaffold 2 } & \multicolumn{2}{c}{ Scaffold 3 } \\
\hline & Counting & Subtraction & Errors & Fractions & Remainders & Patterns & Representations \\
\hline Highlighting & 1 & 1 & 2 & 1 & 0 & 1 & 2 \\
\hline Masking & 2 & 2 & 2 & 1 & 1 & 1 & 1 \\
\hline Video Complexity & 1 & 1 & 0 & 0 & 1 & 0 & -1 \\
\hline
\end{tabular}

Given our findings, we revisit our Video Complexity Rubric presented in Table 1, realigning the significant intrinsic and extraneous load categories into two new dimensions that comport with video complexity, namely highlighting and masking of CMT. Table 6 shows the result, with the category of Teacher Participation reverse coded due to its negative effect. It is worth noting that we do not suggest teacher educators solely seek to maximize highlighting features and minimize masking features when designing or implementing video with PSTs. Rather, we suggest that understanding the implications for the varying complexities of video representations of authentic classrooms is necessary for instructional design. Toward this end, Figure 8 presents the relationship of highlighting and masking dimensions of videocase complexity.

Reflecting on our instructional platform, BLINDED, the implication of our findings, and the relationship of highlighting and masking of video representations, we reduced the overall scores of our seven videocases into the two dimensions, highlighting and masking, as shown in Table 8. In the next iteration of our work, our findings suggest PSTs' development of noticing of CMT may improve if videocase complexity is also scaffolded, both within and across the original scaffolding in the BLINDED platform. For example, more complex videocases such as Counting or Subtraction may be used later in the course after PSTs have had opportunities to engage with less complex videocases such as Errors or Fractions.

Several limitations are worth noting. Notably, sequential moments of CMT did not impact PST noticing. This may be a result of the design of the BLINDED platform wherein PSTs were able to pause the videos at their leisure. Further, Clarity of Student Thinking did not significantly impact PST noticing. Rather than implying clarity of CMT does not highlight or mask CMT, we contend that the platform design, notably the pop-ups telling when PSTs should attend to CMT and the focus questions guiding PSTs where to attend both obscured the degree of clarity of CMT within the videos, confounded our results.

Overall, these results have certain implications for the design and use of video representations to support and develop PSTs' skills at noticing CMT. First, results of our study demonstrate that the complexity of video representations significantly impact PST noticing. Indeed, in our prior work, we suggested that video 
representations used in such settings are not all created equal in terms of the teaching and learning interactions that are made visible to the viewer (Castro Superfine et al., 2017). Other research similarly points to the importance of considering the nature of video representations used to support teacher learning over time (Sherin, Linsenmeier, \& van Es, 2009).

Moving forward, teacher educators should carefully consider the particular nature of video representations used with PSTs and scaffold their noticing according to the teaching and learning events that are made transparent or masked in the video. In the context of our work, for example, certain videos were coded as having higher cognitive load as shown in Table 5. Coupled with our results, this suggests that implementation of the videos should be re-ordered according to the presence and absence of certain features as implied by these video ratings, in order to better scaffold PST noticing over time. Such features include: cognitively demanding tasks that evoke multiple and different solution strategies from children; child thinking that is presented in group/simultaneous contexts rather than individually and sequentially; videos with minimal teacher interaction related to CMT; and videos that minimize the number of moments not related to CMT. Videos with these features might be used at the beginning of a course, with videos that have several moments not related to CMT used later in the course. Focus questions used alongside such videos might also be revised to indicate moments non-essential to the task of noticing CMT, scaffolding what novice teachers should not attend to. Such revisions to the design and use of the BLINDED video representations may better support PST noticing of CMT across a semester-long course. As research on noticing continues to evolve, researchers should consider the nature of video representations used to support teacher learning, particularly the relationship between the complexity of video representations and what is noticed.

\section{REFERENCES}

Alsawaie, O. N., \& Alghazo, I. M. (2010). The effect of video-based approach on prospective teachers' ability to analyze mathematics teaching. Journal of Mathematics Teacher Education, 13(3), 223-241. https:/ / doi.org/10.1007/s10857-009-9138-8

American Statistical Association. (2007). Using statistics effectively in mathematics education research. Washington, DC: American Statistical Association.

Ball, D., \& Cohen, D. (1999). Developing practice, developing practitioners. In L. Darling-Hammond \& G. Sykes (Eds.), Teaching as the learning profession (pp. 3-32). San Francisco, CA: Jossey-Bass Publishers.

Ball, D., Thames, M., \& Phelps, G. (2008). Content knowledge for teaching: What makes is so special? Journal of Teacher Education, 59, 389-407. https:/ / doi.org/10.1177/0022487108324554

Blomberg, G., Sturmer, K., \& Seidel, T. (2011). How pre-service teachers observe teaching on video: Effects of viewers' teaching subjects and the subject of the video. Teaching and Teacher Education, 27, 1131-1140. https:/ / doi.org/10.1016/j.tate.2011.04.008

Brophy, J. (2004). Using video in teacher education. New York, NY: Emerald Group Publishing.

Castro Superfine, A., Fisher, A., Bragelman, J., \& Amador, J. (2017). Shifting perspectives on preservice teachers' noticing of children's thinking. In E. Schack, M. Fisher, \& J. Wilhem (Eds.), Teacher Noticing: Bridging and Broadening Perspectives, Contexts and Frameworks (pp. 409-426). Springer International Publishing.

Castro Superfine, A., Li, W., Bragelman, J., \& Fisher, A. (2015). Examining the use of video to support preservice elementary teachers' noticing of children's thinking. Journal of Technology and Teacher Education, 23(2), 137157.

Chamberlin, M. (2005). Teacher discussions of students' thinking: Meeting the challenge of attending to students' thinking. Journal of Mathematics Teacher Education, 8(2), 141-170. https:/ / doi.org/10.1007/s10857-005-4770-4

Chandler, P., \& Sweller, J. (1992). The split-attention effect as a factor in the design of instruction. British Journal of Educational Psychology, 62(2), 233-246. https:// doi.org/10.1111/j.2044-8279.1992.tb01017.x

Fitzmaurice, G. M., Laird, N. M., \& Rotnitzky, A. G. (1993). Regression models for discrete longitudinal responses. Statistical Science, 8(3), 284-309. https://doi.org/10.1214/ss/1177010903

Hatch, T. \& Grossman, P. (2009). Learning to look beyond the boundaries of representations: Using technology to examine teaching. Journal of Teacher Education, 60, 70-85. https:/ / doi.org/10.1177/0022487108328533

Homer, B. D., Plass, J. L., \& Blake, L. (2008). The effects of video on cognitive load and social presence in multimedialearning. Computers in Human Behavior, 24, 787-797. https:/ / doi.org/10.1016/j.chb.2007.02.009

Inan, G., \& Wang, L. (2017). PGEE: An R package for analysis of longitudinal data with high-dimensional covariates. The R Journal, 9(1), 393-402.

Jacobs, V. R., Lamb, L. L. C., \& Philipp, R. A. (2010). Professional noticing of children's mathematical thinking. Journal for Research in Mathematics Education, 41(2), 169-202. 
Kazemi, E., \& Stipek, D. (2001). Promoting conceptual thinking in four upper-elementary mathematics classrooms. The Elementary School Journal, 102(1), 59-80. https:/ / doi.org/10.1086/499693

Kenward, M. G., Lesaffre, E., \& Molenberghs, G. (1994). An application of maximum likelihood and generalized estimating equations to the analysis of ordinal data from a longitudinal study with cases missing at random. Biometrics, 50(4), 945-953. https:/ / doi.org/10.2307/2533434

Lee, H., Plass, J. L., \& Homer, B. D. (2006). Optimizing cognitive load for learning from computer-based science simulations. Educational Psychologist, 902-913.

Masats, D. \& Dooly, M. (2011). Rethinking the use of video in teacher education: A holistic approach. Teaching and Teacher Education, 27, 1151-1162. https:/ / doi.org/10.1016/j.tate.2011.04.004

Mayer, R. E., \& Moreno, R. (2003). Nine ways to reduce cognitive load in multimedia learning. Educational Psychologist, 38(1), 43-52. https://doi.org/10.1207/S15326985EP3801_6

Paa, F., Renkl, A., \& Sweller, J. (2003). Cognitive load theory and instructional design: Recent developments. Educational Psychologist, 38(1), 1-4. https:/ / doi.org/10.1207/S15326985EP3801_1

Pang, J. (2011). Case-based pedagogy for prospective teachers to learn how to teach elementary mathematics in Korea. ZDM Mathematics Education, 43, 777-789. https:/ / doi.org/10.1007/s11858-011-0352-3

Philipp (Eds.), Mathematics teacher noticing (pp. 117-133). New York: Routledge.

Santagata, R., Zannoni, C., \& Stigler, J. W. (2007). The role of lesson analysis in pre-service teacher education: An empirical investigation of teacher learning from a virtual video-based field experience. Journal of mathematics teacher education, 10(2), 123-140. https:/ / doi.org/10.1007/ s10857-007-9029-9

Sharpe, L., Hu, C., Crawford, L., Gopinathan, S., Khine, M., Moo, S., \& Wong, A. (2003). Enhancing multipoint desktop video conferencing (MDVC) with lesson video clips: Recent developments in pre-service teachers practice in Singapore. Teaching and Teacher Education, 19, 529-541. https://doi.org/10.1016/S0742051X(03)00050-7

Sherin, M. G., \& van Es, E. (2009). Effects of video club participation on teachers' professional vision. Journal of Teacher Education, 60(1), 20-37. https:/ / doi.org/10.1177/0022487108328155

Sherin, M. G., \& van Es, E. A. (2005). Using video to support teachers' ability to notice classroom interactions. Journal of Technology and Teacher Education, 13, 475-491.

Sherin, M. G., Jacobs, V. R., \& Phillip, R. (2011). Mathematics teacher noticing: Seeing through teachers' eyes. New York, NY: Routledge. https:/ / doi.org/10.4324/9780203832714

Sherin, M. G., Linsenmeier, K., van Es., E. (2009). Selecting video clips to promote mathematics teachers' discussion of student thinking. Journal of Teacher Education, 60(3), 213-230. https:/ / doi.org/10.1177/0022487109336967

Star, J. R., \& Strickland, S. K. (2008). Learning to observe: Using video to improve preservice teachers' ability to notice. Journal of Mathematics Teacher Education, 11, 107-125. https:/ / doi.org/10.1007/s10857-007-9063-7

Star, J., Lynch, K., \& Perova, N. (2011). Using video to improve preservice mathematics teachers' abilities to attend to classroom features. In M. G. Sherin, V. Jacobs, \& R.

Stein, M. K., Engle, R., Smith, M., \& Hughes, E. (2015). Orchestrating productive mathematics discussions: Helping teachers learn to better incorporate student thinking (pp. 375-388). In L. Resnick, C. Asterhan, \& S. Clarke (Eds.), Socializing intelligence through academic talk and dialogue. Washington, DC: American Educational Research Association. https://doi.org/10.3102/978-0-935302-43-1_29

Stein, M., Smith, M., Henningsen, M., \& Silver, E. (2000). Implementing standards-based mathematics instruction. New York, NY: Teachers College Press.

Sweller, J. (2003). Evolution of human cognitive architecture. In B. H. Hoss (Ed.), The psychology of learning and motivation: Advances in research and theory (pp. 216-266). San Diego, CA: Academic Press.

Tekkumru Kisa, M., \& Stein, M. K. (2015). Learning to see teaching in new ways: A foundation for maintaining cognitive demand. American Educational Research Journal, 52(1), 105-136. https://doi.org/10.3102/0002831214549452

van Es, E. \& Sherin, M. (2008). Mathematics teachers' "learning to notice" in the context of a video club. Teaching and Teacher Education, 24, 244-276. https:/ / doi.org/10.1016/j.tate.2006.11.005

van Es, E. (2011). A framework for learning to notice student thinking. In M. G. Sherin, V. R. Jacobs, \& R. Phillip (Eds.), Mathematics teacher noticing: Seeing through teachers' eyes (pp. 165-180). New York, NY: Routledge.

van Merriënboer, J. J. G., Kirschner, P. A., \& Kester, L. (2003). Taking the load off a learner's mind: Instructional design for complex learning. Educational Psychologist, 38(1), 5-13. https:/ / doi.org/10.1207/S15326985EP3801_2 
Zeger, S. L., \& Liang, K. (1986). Longitudinal data analysis for discrete and continuous outcomes. Biometrics, 42(1), 121-130. https:/ / doi.org/10.2307/2531248

Zorn, C. J. (2001). Generalized estimating equation models for correlated data: A review with applications. American Journal of Political Science, 45(2), 470-490. https:/ / doi.org/10.2307/2669353

\section{APPENDIX A}

\section{BLINDED Videocase Curriculum Overview}

\section{Overview}

This video-based curriculum was designed as a supplementary resource to be used in mathematics content courses for preservice elementary teachers. The materials, based on videos from actual elementary classroom lessons, are designed to support preservice elementary teachers in developing their understanding of children's mathematical thinking, with a particular focus on understanding the mathematical concepts and ideas underlying children's thinking.

The BLINDED curriculum consists of nine videocases, each consisting of a video clip(s), transcripts, a set of viewing questions, a facilitator guide, and any related classroom lesson materials and/or child work samples. The video clips range from 4-15 minutes in duration, and are edited clips from lessons videotaped in actual elementary mathematics classrooms (grades K-5). Each videocase has been designed to focus on elementary level mathematical topics ranging from whole and rational number concepts and operations to algebraic thinking. Facilitator guides, transcripts, classroom lesson materials and child work samples are in a printable PDF format on CD.

\section{Overarching goals of the BLINDED curriculum}

The BLINDED curriculum is designed to provide preservice elementary teachers with opportunities to attend to and analyze the complexities in children's mathematical thinking as it arises in actual classroom practice. The goal of the curriculum is to support preservice elementary teachers in developing their knowledge and understanding of children's thinking in order that they are better prepared to anticipate, make sense of, and support children's mathematical thinking in their future work as teachers. The videocases are designed around the following mathematics content and mathematical tasks of teaching:

\begin{tabular}{|c|c|c|}
\hline Videocase Title & Mathematics Topics & Mathematical Tasks of Teaching \\
\hline Finding Patterns & Algebra & $\begin{array}{l}\text { Evaluating the plausibility of children's claims } \\
\text { Asking productive mathematical questions }\end{array}$ \\
\hline Counting Strategies & $\begin{array}{l}\text { Meaning of addition, } \\
\text { subtraction; Addition, } \\
\text { subtraction problem } \\
\text { types }\end{array}$ & $\begin{array}{l}\text { Evaluating children's mathematical explanations } \\
\text { Asking productive mathematical questions }\end{array}$ \\
\hline $\begin{array}{l}\text { Understanding Place } \\
\text { Value }\end{array}$ & Counting; Place value & Analyzing children's thinking \\
\hline $\begin{array}{l}\text { Modeling Double-Digit } \\
\text { Subtraction }\end{array}$ & Subtraction algorithm & Linking representations to underlying mathematical ideas \\
\hline Debating Remainders & $\begin{array}{l}\text { Division; Remainder } \\
\text { interpretation }\end{array}$ & $\begin{array}{l}\text { Evaluating children's mathematical arguments } \\
\text { Asking productive mathematical questions }\end{array}$ \\
\hline $\begin{array}{l}\text { Student Errors with } \\
\text { Multiplication \& } \\
\text { Division Algorithms }\end{array}$ & $\begin{array}{l}\text { Place value; Standard, } \\
\text { alternative } \\
\text { multiplication \& } \\
\text { division algorithms }\end{array}$ & Analyzing children's errors \\
\hline Pattern Block Fractions & $\begin{array}{l}\text { Relationship between } \\
\text { improper fractions and } \\
\text { mixed numbers }\end{array}$ & $\begin{array}{l}\text { Analyzing children's thinking } \\
\text { Analyzing children's errors }\end{array}$ \\
\hline $\begin{array}{l}\text { Why is } 1 / 20 \text { not equal } \\
\text { to } 20 \% ?\end{array}$ & $\begin{array}{l}\text { Relationship between } \\
\text { percentages and } \\
\text { decimals }\end{array}$ & $\begin{array}{l}\text { Analyzing children's errors } \\
\text { Linking representations to underlying mathematical ideas }\end{array}$ \\
\hline $\begin{array}{l}\text { The Fundraising } \\
\text { Problem: Multiple } \\
\text { Solution Strategies }\end{array}$ & $\begin{array}{l}\text { Fractions; Liner } \\
\text { functions }\end{array}$ & Evaluating children's mathematical explanations \\
\hline
\end{tabular}




\section{Overview of videocases}

The videocases are comprised of a video clip(s) and a set of viewing questions in order that preservice elementary teachers can watch the video clip(s) through the lens of the questions, and then discuss their responses to the questions with their peers. Each videocase takes about 30 minutes to complete. The nine videocases are briefly described below:

Finding Patterns comes from a fourth grade class where students are working in small groups on the Many-Eyed Octupi task, which involves identifying patterns, and describing patterns using words, data tables, and symbols. Students are asked to create a data table in order to determine the number of eye squares of different aged Octupi, eventually determining the number of eye squares in any aged Octupi. In doing so, many students use colored tiles in order to build the different aged Octupi. The goals of this videocase for preservice teachers include analyzing student thinking, evaluating the plausibility of students' strategies, and asking productive mathematical questions. In particular, this case addresses patterns in mathematics, presenting the pattern in different ways, and articulating how one knows that a given pattern will continue. It also highlights how students begin to find a given pattern and how they know whether a pattern will continue growing in a certain way.

Counting Strategies comes from a third grade class where students are discussing their solutions to different problems involving multi-digit addition and subtraction. The problem they are discussing requires various strategies, skills and operations. In doing so, students propose several different strategies for solving the same problem. The goals of this videocase for preservice teachers include identifying and evaluating students' solution strategies. In particular, this case highlights different counting strategies employed by students in problems involving addition and subtraction. It also addresses the use of different addition and subtraction problem types that students typically use, often without formal instruction.

Understanding Place Value involves four third grade students who are each being interviewed about what they know about place value, and addition and subtraction algorithms. Specifically, students are asked to represent the quantity represented by different place values in a given number. The goals of this videocase for preservice teachers include analyzing student thinking and determining what students understand about a particular concept. In particular, this case addresses students' understanding of place value as they work with and operate on different numbers. It also reveals how students perceive different numbers.

Modeling Double-Digit Subtraction with Base Ten Blocks comes from a fourth grade class where students are discussing double-digit subtraction using base-ten blocks. This case emphasizes potential uses of a particular manipulative (i.e., base ten blocks) to make visible the role of place value in the multi-digit subtraction algorithm, which is can often be a source of error for elementary students. It also highlights the importance of mapping between concrete and static representations of numbers to reinforce the connections between the two representations. The goals of this videocase for preservice teachers include understanding the role of base ten blocks and place value in the subtraction algorithm, analyzing student thinking, and evaluating the plausibility of students' strategies. In particular, this case addresses the role of place value in the double-digit subtraction algorithm, and the ways in which base ten blocks can make visible the role of place value in the algorithm. It also highlights how students can make sense of the subtraction algorithm using base ten blocks.

Debating Remainders comes from a third grade class where students are working in small groups on the Birthday Party task, which requires students to use division to solve different problem situations using both written explanations and pictures. Students have to interpret the remainder in the context of different situations. The goals of this videocase for preservice teachers include evaluating students' explanations and asking productive mathematical questions that support students' thinking without diminishing the importance of their strategies. This case addresses the relationship between multiplication and division. It also highlights students' thinking about the task, particularly the ways in which students negotiate a correct answer to the problem.

Student Errors with Multiplication and Division Algorithms comes from a fourth grade class that is working on problems requiring different multiplication and division algorithms, including partial products, long division, and the forgiving method. As they are working in small groups on the problems, some students make certain errors in their work. This case emphasizes the role of student errors in instruction as they relate to multiplication and division algorithms. The goal of this videocase for preservice teachers includes analyzing children's errors. This case highlights the fundamental role of place value in whole number algorithms.

Pattern Block Fractions comes from a fifth grade class who is exploring fractions using pattern blocks and fraction sentences. Specifically, students are working on modeling fractions greater than one with pattern blocks, and writing improper fractions as mixed numbers and vice versa. This case highlights students' thinking about finding equivalent fractions, particularly with pattern blocks, and the ways in which students can make sense of converting improper fractions to mixed numbers and vice versa. The goals of this videocase for preservice teachers include analyzing student thinking and evaluating the plausibility of students' strategies. In particular, this case addresses 
the relationship between improper fractions and mixed numbers, and the potential role of manipulatives in supporting students' understanding of this relationship.

Why Is $1 / 20$ Not Equal To $20 \%$ involves fifth graders who are working on representing numbers as fractions, decimals and percents. One model, namely the centiwheel, is used to support students' understanding of the relationship among these different symbolic presentations. This case addresses the relationship among fractions, decimals and percents. It also reveals students' misconceptions about the translation between fractions and decimals, as well as the translation between decimals and percents. The goals of this videocase for preservice teachers include analyzing student thinking, evaluating the plausibility of students' strategies, and asking productive mathematical questions. In particular, this case addresses mathematical representations, and representing numbers in different ways. It also highlights common misconceptions students' have related to decimals and percents, and the potential role of mathematical models (i.e., centiwheels) in supporting students' understanding.

The Fundraising Problem involves a sixth-grade class who are working in small groups on the Fundraising Problem. Students are asked to use fraction strips to measure the amount of money collected every two days. They then use the data collected from the previous ten days in order to predict if the class will meet their fundraising goal by day 12. In doing so, different small groups generate different solution strategies for the problem. The goals of this videocase for preservice teachers include analyzing student thinking and evaluating the plausibility of students' strategies. In particular, this case addresses different ways in which students interpret data. It also highlights how diverse students' thinking can be when working on the same problem.

\section{http://www.ejmste.com}

